\title{
Peertechz
}
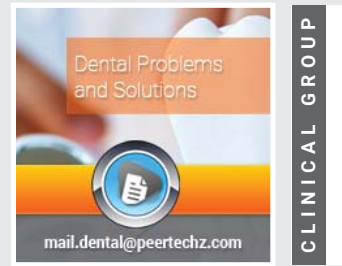

Research Article

\section{Evaluation of papillo-incisal distance in different arch forms and with different shapes of incisive papilla in Moradabad population - A descriptive study}

Received: 04 May, 2021

Accepted: 21 May, 2021

Published: 22 May, 2021

*Corresponding author: Dr. Samarth Kumar Agrawal, Professor, Department of Prosthodontics and Crown and Bridge, Kothiwal Dental College and Research Centre, India, Tel: 9837214936;

E-mail:dr.samarthagarwal@yahoo.co.in

Keywords: Shape of incisive papilla; Papilla- incisor distance; Arch form

https://www.peertechzpublications.com

\section{Check for updates}

\section{Samarth Kumar Agrawal1*, Romil Singhal1, Shradha Pagia² and Kumari Kalpana ${ }^{3}$}

${ }^{1}$ Professor, Department of Prosthodontics and Crown and Bridge, Kothiwal Dental College and Research Centre, India

${ }^{2}$ Private Practitioner, Department of Prosthodontics and Crown and Bridge, Kothiwal Dental College and Research Centre, India

${ }^{3}$ Post Graduate Student, Department of Prosthodontics and Crown and Bridge, Kothiwal Dental College and Research Centre, India

\section{Abstract}

Error in placement of maxillary anterior teeth in complete denture contributes to artificial senile appearance, thus not satisfying the aesthetic values that patient deserves.

Material and Method: A total of 249 patients were selected between 17-40 years of age. Patients had normal dentition, well aligned arches with all teeth present. Arch form was assessed by using 3M Unite template. Shape of incisive papilla was marked on cast. Measurement of horizontal distance between posterior border of incisive papilla and labial surface of maxillary central incisor was done with digital vernier caliper.

Result: Square form had minimum mean distance $(11.76+1.59 \mathrm{~mm})$. Tapered form had maximum mean distance (12.43=1.74 mm). For ovoid form, the mean distance was $12.19+1.24 \mathrm{~mm}$. Overall, cylindrical shape was the most common (34.1\%) followed by pear (26.5\%), flame (20.1\%) and dumbel or round shape (6\% each). Statistical evaluation revealed that there was no significant difference among different arch forms with respect to shape of incisive papilla.

Conclusion: Distance between incisive papilla and maxillary central incisor is independent of arch form and shape of Incisive papilla.

\section{Introduction}

Esthetics is the prime concern of patient seeking prosthetic treatment. The pre-maxilla is referred to as an "esthetic zone" because of its high visibility and influence on facial appearance. Improper positioning of maxillary centrals incisor may result in distorted appearance and may affect speech also. To achieve natural appearance in complete dentures, the upper anterior teeth should be positioned as close as possible to the original position occupied by the natural teeth. To achieve this goal pre-extraction records helps in positioning the teeth in relation to the general arch form and one another. But pre- extraction records are either not available or lost due to negligence. The prosthodontist may have to rely only on the anatomic landmarks for teeth arrangement [1]. One guide to the anteroposterior arrangement of the anterior teeth is its relationship with the incisive papilla, which is a reliable and relatively stable anatomic landmark. 
The incisive papilla is a small mucosal prominence situated at the midline of the palate, posterior to the palatal surface of the central incisors. It is seen in various shapes; it may be discrete or continuous with the interdental papilla of the upper central incisors [2]. The incisive papilla can be divided into three parts: anterior, middle and posterior [3].

The horizontal relationship between incisive papilla and the maxillary central incisors in the dentulous subjects is a guide to position the central incisor teeth as nearly as possible in their original location to restore labial contour in edentulous subjects.

Arch form has been described by various researchers and clinicians. It refers to the overall configuration of the dental arch and considers symmetry, roundness, elongation and convexiti [4]. Numerous algebraic or geometric formula has been used to denote arch form as ellipse, parabola, segments of circles joined to straight lines, modified spheres, catenary curve as well as mathematic formula such as the cubic spline, conic section and polynomial function. Several classification schemes have been suggested, but the most commonly used is the one advocated by Chuck in 1932 who classified arch form as tapered, ovoid, and square [5]. The knowledge of arch from as an anatomical parameter is of considerable relevance in positioning of anterior teeth for removable dental prosthesis [6].

The present study evaluated the shapes of incisive papilla and to compare the papilla- incisal distance in different arch form and with different shapes of incisive papilla in Moradabad population.

\section{Material and method}

This descriptive study was done for a period of 6 months with non-probability convenience sampling. Total 249 patients aged between 17 to 40 years with well aligned arches up to second premolars teeth were included in this study. Subjects with any prosthetic, orthodontic or restorative treatment on maxillary anterior teeth, caries in maxillary anterior teeth, malposed or malformed anterior teeth, periodontal disease, congenital and/or acquire maxillary defect or with anterior crowding were excluded in this study. All subjects were selected by short clinical history and examination. involving name, age, sex, facial profile, and any history of previous dental treatment. Consent form was signed by all the subjects. Address verification was done either by domicile, passport, aadhar number or by the voter id card.

Maxillary alginate impression was made for all the subjects and dental stone cast was made. Arch form on each cast was determined using 3M UniteK templates. These templates have square, tapered or ovoid form drawn on it. The cast were placed over each template and checked for its arch form (Figure 1). The arch form was determined on the basis that all the teeth on the cast lied within the outline of the arch form drawn on the template.

On each cast incisive papilla was outlined by led pencil to determine the shape. To measure the papillo - incisal distance the posterior border of the incisive papilla, and the mesial incisal edge of central incisor were marked with lead pencil (Figure 2). A horizontal line was marked at the base of the incisive papilla. A second line was marked in the mid sagittal plane to bisect the papilla. The point of intersection was taken as the reference point for measurement. Papillaincisor distance was recorded to the tenth of a millimetre by the digital vernier calliper to contact the reference point at the base of the incisive papilla and the mesio-incisal point angle of central incisor (Figure 3). After all measurements, i.e., distance between different shapes of incisive papilla in different arch form were recorded and statisticaliy analysed.

\section{Results}

Eight shapes of incisive papilla were observed in all the subjects. Overall, cylindrical shape of incisive papilla was the most common $(n=85 ; 34.1 \%)$ followed by pear shape $(n=66$; $26.5 \%)$, flame shape $(n=50 ; 20.1 \%)$ and round shape $(n=15 ;$ $6 \%$ each). Double shaped, bowling and notched shaped papillae

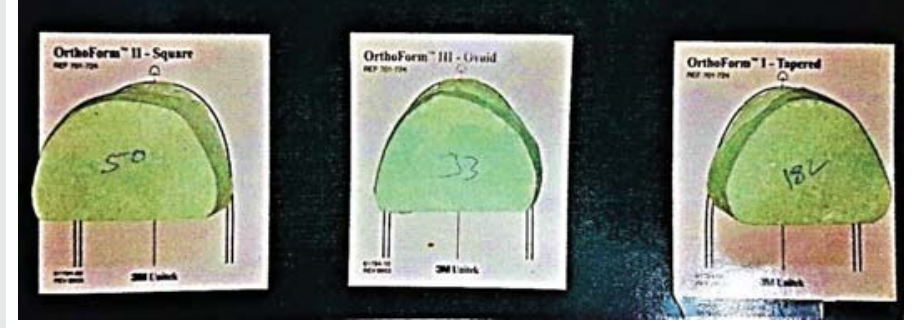

Figure 1: Cast placed over template to determine arch form. 1(a) Square 1(b) Ovoid 1(c) Tapered.

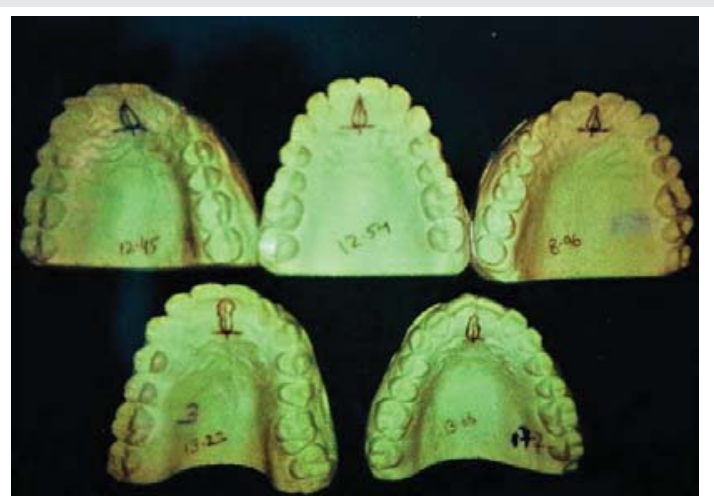

Figure 2: Different shapes of incisive papilla.

2(a)Round 2(b) Flame 2(c) Pear, 2(d) Dumbel 2(e) Cylindrical.

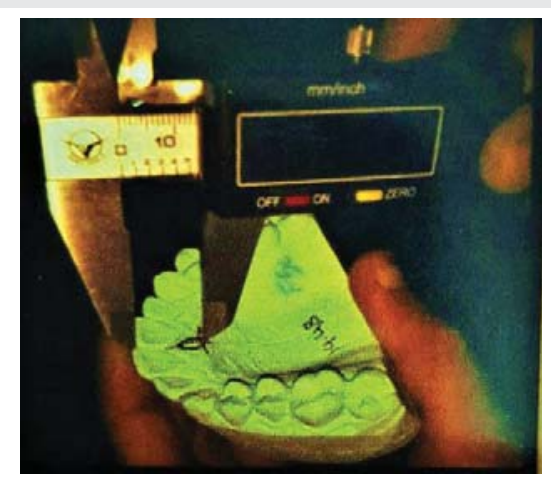

Figure 3: Measuring papilla-incisal distance. 
were relatively less common shape and were observed in 7 $(2.8 \%), 8(3.2 \%)$ and $3(1.2 \%)$ samples only (Table 1$)$. However, Double shape, bowling shape and notched shape were too fewer in number to have a statistical impact. Hence, they were subclassified as "others".

Ovoid arch form was the most prevalent arch form with a total of $163(65.5 \%)$ samples followed by square $(n=67 ; 26.9 \%)$ and tapered $(n=19 ; 7.6 \%)$ arch forms respectively.

The distance of incisive papilla distance and maxillary central incisor in (Tables 2,3) square form had minimum mean value $(11.76 \pm 1.59 \mathrm{~mm})$ whereas tapered form had maximum mean value $(12.43 \pm 1.74 \mathrm{~mm})$. For ovoid form, the mean distance was $12.19 \pm 1.24 \mathrm{~mm}$. Analysis of variance did not show a significant difference among arch forms $(p=0.058)$. The box plot showed an overlapping interquartile range of distance values in all the groups. Statistically, there was no significant difference among different arch forms with respect to shape of incisive papilla $(\mathrm{p}>0.05)$

Tables 1,2 showed the variations in the distance of incisive papilla and maxillary central incisor with different shapes of incisive papilla. The maximum distance was with pear shape $11.26 \mathrm{~mm}$ while lowest in round shape $11.26 \mathrm{~mm}$. The different shapes of incisive papillae and the association between arch form for the distance between incisive papilla and maxillary central incisor did not showed a significant outcome (Tables 1,4). Thus, the distance between incisive papilla and maxillary central incisor is independent of arch form and papillary shape.

\section{Discussion}

The present study was conducted to measure the distance

Table 1: Distribution of samples according to arch form and shapes of incisive papilla.

\begin{tabular}{|l|c|c|c|c|c|c|c|c|c|}
\hline SN & Shape & \multicolumn{2}{|c|}{$\begin{array}{c}\text { Ovoid } \\
(\mathbf{n = 1 6 3})\end{array}$} & \multicolumn{2}{|c|}{$\begin{array}{c}\text { Square } \\
(\mathbf{n = 6 7})\end{array}$} & \multicolumn{2}{|c|}{ Tapered (n=19) } & \multicolumn{2}{|c|}{$\begin{array}{c}\text { Total } \\
(\mathbf{n = 2 4 9})\end{array}$} \\
\hline & & No. & $\%$ & No. & $\%$ & No. & $\%$ & No. & $\%$ \\
\hline 1. & Pear & 48 & 29.4 & 13 & 19.4 & 5 & 26.3 & 66 & 26.5 \\
\hline 2. & Cylindrical & 53 & 32.5 & 24 & 35.8 & 8 & 42.1 & 85 & 34.1 \\
\hline 3. & Flame & 34 & 20.9 & 13 & 19.4 & 3 & 15.8 & 50 & 20.1 \\
\hline 4. & Dumbel & 9 & 5.5 & 5 & 7.5 & 1 & 5.3 & 15 & 6.0 \\
\hline 5. & Round & 9 & 5.5 & 6 & 9.0 & 0 & 0.0 & 15 & 6.0 \\
\hline 6. & Double & 4 & 2.5 & 2 & 3.0 & 1 & 5.3 & 7 & 2.8 \\
\hline 7. & Bowling & 5 & 3.1 & 3 & 4.5 & 0 & 0.0 & 8 & 3.2 \\
\hline 8. & Notched & 1 & 0.6 & 1 & 1.5 & 1 & 5.3 & 3 & 1.2 \\
\hline
\end{tabular}

Table 2: Comparison of distance between incisive papilla and maxillary central incisor for different shapes in different arch forms.

\begin{tabular}{|c|c|c|c|c|c|c|c|c|c|c|c|c|}
\hline \multirow[t]{2}{*}{ SN } & \multirow[t]{2}{*}{ Shape } & \multicolumn{3}{|c|}{ Ovoid ( $n=163$ ) } & \multicolumn{3}{|c|}{ Square $(n=67)$} & \multicolumn{3}{|c|}{ Tapered $(n=19)$} & \multicolumn{2}{|c|}{$\begin{array}{c}\text { Statistical } \\
\text { Significance } \\
\text { (ANOVA) }\end{array}$} \\
\hline & & $\mathbf{n}$ & Mean & SD & $n$ & Mean & SD & $\mathbf{n}$ & Mean & SD & $\mathbf{F}$ & $\mathbf{P}$ \\
\hline 1. & Pear & 48 & 12.36 & 1.36 & 13 & 12.24 & 1.99 & 5 & 12.85 & 1.47 & 0.298 & 0.743 \\
\hline 2 & Cylindrical & 53 & 12.04 & 1.22 & 24 & 11.84 & 1.57 & 8 & 12.97 & 2.01 & 1.949 & 0.149 \\
\hline 3 & Flame & 34 & 12.43 & 1.17 & 13 & 11.77 & 0.97 & 3 & 11.94 & 1.57 & 1.663 & 0.201 \\
\hline 4 & Dumbel & 9 & 12.16 & 0.86 & 5 & 10.93 & 1.34 & 1 & 10.55 & - & 2.815 & 0.099 \\
\hline 5 & Round & 9 & 11.19 & 1.32 & 6 & 11.36 & 2.31 & 0 & - & - & 0.033 & 0.859 \\
\hline 6 & Others & 10 & 12.27 & 0.96 & 6 & 11.47 & 1.33 & 2 & 10.95 & 0.81 & 1.793 & 0.200 \\
\hline
\end{tabular}

Table 3: Comparison of distance between incisive papilla and maxillary central incisor for different shapes of incisive papilla (Combined- all arch forms).

\begin{tabular}{|c|c|c|c|}
\hline Shape of papilla & N & Mean & SD \\
\hline Pear & 66 & 12.37 & 1.49 \\
\hline Cylindrical & 85 & 12.07 & 1.42 \\
\hline Flame & 50 & 12.23 & 1.15 \\
\hline Dumbel & 15 & 11.65 & 1.17 \\
\hline Round & 15 & 11.26 & 1.70 \\
\hline Others & 18 & 11.86 & 1.14 \\
\hline Total & 249 & 12.09 & 1.39 \\
\hline
\end{tabular}

Table 4: Comparison of distance between incisive papilla and maxillary central incisor in different arch forms (combined- all shapes).

\begin{tabular}{|l|l|l|l|}
\hline Arch Form & N & Mean & SD \\
\hline Ovoid & 163 & 12.19 & 1.24 \\
\hline Square & 67 & 11.76 & 1.59 \\
\hline Tapered & 19 & 12.43 & 1.74 \\
\hline Total & 249 & 12.09 & 1.39 \\
\hline
\end{tabular}

between incisive papilla and central incisor in different arch form with different shapes of incisive papilla in Moradabad north India population. The incisive papilla is an important landmark as it is an immobile structure and usually does not shift in adult life. The researchers have used incisor to incisive papilla distance as a biometric guide [7]. Many geometric arch forms and mathematical functions have been proposed to describe dental arches over the years. Some authors classify dental arches into ovoid, tapering and square, this classification of arch forms was used in the present study. The determination of arch form using 3M Unite template was used as it is simple, clinically convenient and quicker.

In the present study the base of the incisive papilla was taken as the reference point for measuring the papillo-incisal distance because it is a reliable landmark as it is definable and subject to least change in the edentulous state. Anterior border and center of incisive papilla are likely to change after extraction of incisor teeth, while the posterior border is relatively stable. During edentulous transformation as the papilla changes its form, its center also changes. There is a shift in the center of the papilla from the dentulous to edentulous state. In dentulous subjects incisive papilla is seen in various shapes and this change will be more in a long papilla compared to a short papilla. Watt and Likeman [8] found that the papilla moved forward about $1.6 \mathrm{~mm}$ because of maxillary alveolar bone resorption and the incisive fossa lies slightly posterior to the papilla [8]. The center/middle or the base/posterior border of the papilla are mostly used as reference for papilla incisor measurements.

Harper ${ }^{9}$ in 1948 , after extensive longitudinal studies on pre-extraction and post extraction models showed that the positional relationship of incisive papilla to the natural teeth offers valuable data in the treatment of edentulous patient. He recognized that the incisive papilla is a dependable landmark to position the upper central incisors in the horizontal and vertical planes in complete denture. He finds the horizontal 
distance between the papilla and central incisor was not less than $5 \mathrm{~mm}$ and not more than $8 \mathrm{~mm}$ [9]. After a decade, McGee [10] recommended to set the labial surface of central incisors $8 \mathrm{~mm}$ anterior to the papilla [9]. Hickey, Boucher and Woelfel [11] in 1962 recommended that the labial surface of central incisors in dentures should be $8-10 \mathrm{~mm}$ anterior to the middle of papilla. Martone [12] in 1963 recommended that incisors should be placed $10 \mathrm{~mm}$ in front of the incisive papilla [12]. Mavroskoufis and Ritchie [13] believed that the incisive papilla is a stable landmark for arranging the labial surfaces of central incisors $10 \mathrm{~mm}$ anterior to the incisive papilla. Mersel A et al., measured the horizontal as well as vertical distance between the posterior border of incisive papilla and the mesial edges of the central incisors [14].

The dental arch form should harmonize with the form of the residual ridge. For example, in square arch form, the distance between canines is wider and posterior ridge arc more parallel and the curvature of anterior ridge is minimum. In ovoid arch form, the distance between the canines is narrower and the curvature of the anterior ridge is more than square arch. In tapering arch form, the distance of canines is narrower, and the curvature of the anterior arch is maximun than any other arches. Nelson contended that the alignment form was a much more important factor than the outline form of the teeth as teeth of same mould looked square in the square alignment, tapered in tapering alignment, and ovoid in ovoid aliment, as the alignment changes for different arch form the distance between the incisive papilla and central incisor would also change with different arch form [15].

In the present study majority of subjects had an ovoid arch form $65.5 \%$ whereas $26.9 \%$ had square and $7.6 \%$ had tapered arch forms. Some of the previous studies have also coated that majority of the subjects had an ovoid arch form, followed by square and then tapered. Distance between central incisor and posterior border of incisive papilla is showed that overall, the mean value of distance between incisive papilla and maxillary central incisor is 12.09. It also showed that square form had minimum mean value $(11.76 \pm 1.59)$ whereas tapered form had maximum mean value (12.43 \pm 1.74$)$ and ovoid form had mean distance of $12.19 \pm 1.24$.

In the present study, on comparing the distance between incisive papilla and maxillary central incisor for different shapes of incisive papilla combining all arch forms in Table 2, pear shaped have maximum mean distance (12.37) round shape have minimum mean distance (11.26). No studies have been done regarding distance between different shapes of incisive papilla and central incisor with different arch forms in north India, so present study cannot direct compare these results with other studies. Previous studies showed less distance because they estimated the distance between the mid-point of the incisive papilla and the mesial edges of the central incisors $[12,16-19]$. Variation of results may be due to the ethnic difference also.

Papilla incisor distance is a useful biometric guide to both the dentist and the dental technician. However, it may not be applicable in every case; clinician should judiciously consider individual variations. Other biometric guides, phonetic tests and clinical judgement should be considered to decide the most appropriate position of central incisors in the horizontal plane. In the laboratory it is a distinct advantage for the technician to develop the labial contour of occlusal rim. Over contouring and under contouring the labial surface of occlusal rim by technician is minimized, simplifying the procedure of obtaining the labial contour of the occlusal rim in patients' mouth, saving chair side time. It is also a valuable guide for the technician to set the incisor and canine teeth particularly when the labial contour of the maxillary occlusal rim is ignored by clinician or not correctly recorded by him [2].

However, the present study has certain limitations, that this study is done only in Moradabad population and the time period for this study was very short. Sample size for different arch form and different shape of incisive papilla was not evenly distributed. It is recommended that further studies be conducted with equally distribution of sample size on a wider population.

\section{Conclusion}

On the basis of results obtained and their analysis, the following conclusions were drawn from the present study:

1) Ovoid form was the most prevalent arch form, followed by square and tapered arch form in Moradabad population.

2) Cylindrical shape was the most common followed by pear shape. flame shape and round shape. Double shaped, bowling and notched shaped papillae were relatively less common in Moradabad population.

3) Among different arch forms, square form had minimum mean value $(11.76 \mathrm{~mm})$ distance whereas tapered form had maximum mean value $(12.43 \mathrm{~mm})$ distance.

4) Shapes of incisive papilla affects the distance between central incisor and incisive papilla.

5) Mean distance between central incisor and incisive papilla in all shapes and arch form in Moradabad population is $11.26-12.37 \mathrm{~mm}$

\section{References}

1. Isa ZM. Abdulhadi LM (2012) Relationship of maxillary incisors in complete dentures to the incisive papilla. J Oral Sci 54: 159-163. Link: https://bit.ly/3fzG5EV

2. Solomon E, Arunachalanm K (2012) The incisive papilla: A significant landmark in prosthodontics. J Indian Prosthodont Soc 12: 236-247. Link: https://bit.ly/34810yg

3. Bing WC, Kwan LL, Isa ZM (2009) Incisive papilla and hamular notches as guides to maxillary anterior teeth size in edentulous patients. Dentika 14: 109 114. Link: https://bit.ly/3f6Z2j8

4. Taiik I, Mushtaj N, Khan M (2011) Arch forms among different angle classification A Study. Pak Med Net 31: 92-95. Link: https://bit.ly/3c1y8Yn

5. Olmze S, Dogan S (2011) Comparison of the arch forms and dimensions in various malocclusions of the Turkish population. OJST 9: 158-164. Link: https://bit.ly/3ugHvcZ 
6. Dharkar N, Jain M (2013) Arch forms An Overview. Univers Res J Dent 3: 16 20.

7. Pachore N, Bhakhar V, Patel J, Patel A, Adeshra K (2017) An in-vivo comparison of vertical and horizontal distance between incisive papilla and incisal edge of maxillary central incisors in dentates with different arch forms. J Clin Diagnostic Res 11: ZC97- ZC100. Link: https://bit.ly/3hlm9CD

8. Watt DM, Likeman PR (1976) Morphological changes in the denture bearing Area following the extraction of maxillary teeth. Br Dent J 136: 225-235. Link: https://bit.ly/2RBXpkz

9. Harper RN (1948) The incisive papilla-basis of technic to reproduce the positions of key teeth in prosthodontia. J Dent Res 27: 661-668. Link: https://bit.ly/3f6Y2vD

10. McGee GF (1960) Tooth Placement and base contour in denture construction. J Prosthet Dent 10: 651-657. Link: https://bit.ly/3wk9n19

11. Hickey JC, Boucher CO, Woelfel JB (1962) Responsibility of the dentist in complete denture construction. J Prosthet Dent 12: 637-653. Link: https://bit.ly/2Rz1N30

12. Martone LC (1963) Clinical application of concepts of functional anatomy and speech science to complete denture prosthodontics. J Prosthet Dent 13: 20 Link: https://bit.ly/3ytkBIW
13. Marvroskoufis F, Ritchie GM (1981) Nasal width and incisive papilla as guides for selection and arrangement of maxillary anterior teeth. J Prosthet Dent 45 592-597. Link: https://bit.ly/3hlYzFJ

14. Mersel A, Ehrlich J (1981) Connection Between Incisive Papilla, Central Incisor and Rugae Canina. Quintessence Int 12: 1327-1329. Link: https://bit.ly/3u6BKOR

15. Pound E (1954) Lost-Fine Arts in the Fallacy of the Ridges. J Prosthet Dent 4 6-16. Link: https://bit.ly/3fEdNJx

16. Agrawal S, Singhal R, Pagia S (2016) Evaluation of papillo-incisal distanc with different shapes of incisive papilla. IJSR 5: 1341-1342. Link: https://bit.ly/3yvpqeg

17. Park Y, Lee S, Paik K (2007) The three-dimensional relationship on a virtual model between the maxillary anterior teeth and incisive papilla. $\mathrm{J}$ Prosthet Dent 98: 312-318. Link: https://bit.ly/2RuxefU

18. Dahiya D, Kalra A, Goel S (2015) Evaluation of maxillary central incisor and canine in relation to inter papilla line: A comparative study. IJERMDC 2: 1-11. Link: https://bit.ly/3f6ZG0j

19. Amin WM, Taha ST, Al-Tarawneh SK, Saleh MW, Ghzawi A (2008) The relationships of the maxillary central incisors and canines to the incisive papilla in Jordanians. J Contemp Dent Pract 9: 42-51. Link: https://bit.ly/3fyEqPT

\section{Discover a bigger Impact and Visibility of your article publication with}

\section{Peertechz Publications}

\section{Highlights}

* Signatory publisher of ORCID

* Signatory Publisher of DORA (San Francisco Declaration on Research Assessment)

- Articles archived in worlds' renowned service providers such as Portico, CNKI, AGRIS TDNet, Base (Bielefeld University Library), CrossRef, Scilit, J-Gate etc.

* Journals indexed in ICMJE, SHERPA/ROMEO, Google Scholar etc.

* OAI-PMH (Open Archives Initiative Protocol for Metadata Harvesting)

* Dedicated Editorial Board for every journal

* Accurate and rapid peer-review process

* Increased citations of published articles through promotions

* Reduced timeline for article publication

Submit your articles and experience a new surge in publication services

(https://www.peertechz.com/submission).

Peertechz journals wishes everlasting success in your every endeavours.

Copyright: () 2021 Samarth Kumar A, et al. This is an open-access article distributed under the terms of the Creative Commons Attribution License, which permits unrestricted use, distribution, and reproduction in any medium, provided the original author and source are credited. 